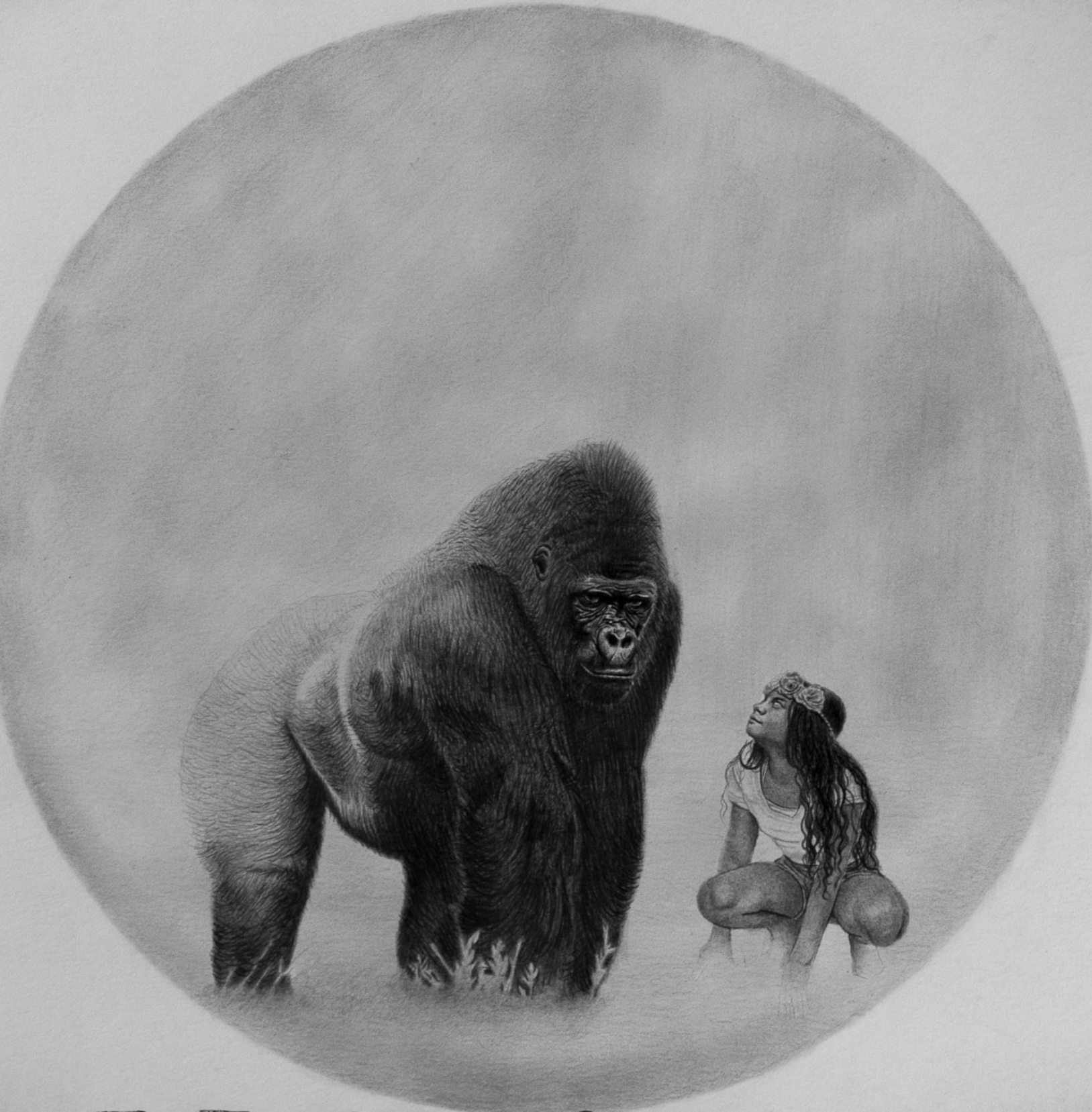

Sin título

De la serie Un viaje hacía el origen

Grafito sobre papel

$24,6 \times 24,9 \mathrm{~cm}$

2019

Medellín 


\title{
Pensar los movimientos sociales en y desde América Latina. Una mirada crítica a la contribución de Raúl Zibechi*
}

\author{
Edwin Cruz Rodríguez (Colombia)**
}

\section{Resumen}

Este artículo reconstruye críticamente la interpretación de los movimientos sociales de Raúl Zibechi. Primero examina las concepciones de los movimientos sociales y las sociedades en movimiento; luego analiza las categorías de comunidad y poderes no-estatales; a continuación, problematiza la noción de autonomía y su relación con la emancipación; y finalmente, analiza su interpretación de los gobiernos progresistas. Las categorías de comunidad, autonomía, poderes no-estatales y las preguntas que plantea son cardinales para pensar la emancipación y la descolonización más allá del Estado. Sin embargo, la idealización de la comunidad, la reducción del Estado a un aparato burocrático y la imprecisión del concepto de movimiento social plantean problemas para analizar sus mutuas relaciones, particularmente en el marco de los gobiernos progresistas. Complejizar la comprensión de los movimientos sociales, resaltando el tipo de acción colectiva que les es propia en vez de identificarlos con sus organizaciones, enriquece el análisis de las infraestructuras que los hacen posibles, las relaciones desiguales de poder en su interior y las múltiples relaciones que establecen con el Estado, más allá de la dicotomía entre autonomía y cooptación.

\section{Palabras clave}

Teoría Política; Movimientos Sociales; Comunidad; Emancipación; Zibechi, Raúl; América Latina.

Fecha de recepción: febrero de 2019 • Fecha de aprobación: junio de 2019

\footnotetext{
* Resultado del proyecto de investigación Movimientos sociales y subjetividades: desafios teóricos desde América Latina, desarrollado por el grupo de investigación Teoría Política Contemporánea (Teopoco), Universidad Nacional de Colombia, con recursos de la institución y bajo orientación del profesor Leopoldo Múnera Ruiz.

** Politólogo. Especialista en Análisis de Políticas Públicas. Magíster en Análisis de Problemas Políticos, Económicos e Internacionales Contemporáneos de la Universidad Externado de Colombia, Candidato a Doctor en estudios políticos y relaciones internacionales e integrante del grupo de investigación Teoría Política Contemporánea (Teopoco), Universidad Nacional de Colombia. Correo electrónico: ecruzr@unal.edu.co - Orcid: 0000-0001-8891-8796
} 


\title{
Cómo citar este artículo
}

Cruz Rodríguez, Edwin. (2019). Pensar los movimientos sociales en y desde América Latina. Una mirada crítica a la contribución de Raúl Zibechi. Estudios Políticos (Universidad de Antioquia), 56, pp. 175-197. DOI: 10.17533/udea.espo. n56a08

\section{Thinking Social Movements in and from Latin America. A Critical View to Raul Zibechi's Contribution}

\begin{abstract}
This article critically reconstructs Raúl Zibechi's view on social movements. First, it examines the conceptions of social movements and societies in movement. Next, it analyzes the categories of community and non-state powers. Third, it problematizes the notion of autonomy and its relation to emancipation. Finally, it analyzes Zibechi's interpretation of progressist governments. The categories of community, autonomy, non-state powers, and the questions they raise are key to thinking about emancipation and decolonization beyond the State. Nevertheless, the idealized vision of community, the reduction of the State to a hierarchical bureaucratic apparatus, and the inaccuracy of the concept of social movement set [176] problems out to analyze their mutual relations, particularly in the context of Latin American progressist governments. Highlighting collective action that belongs to social movements, instead of identify them with their organizations, increases a complex understanding of them, and enhances the analysis of the infrastructures that make them possible, the unequal power relations within them and its several relations to the State, beyond the dichotomy between autonomy and cooptation.
\end{abstract}

\section{Keywords}

Political Theory; Social Movements; Community; Emancipation; Zibechi, Raúl; Latin America. 
Pensar los movimientos sociales en y desde América Latina. Una mirada crítica...

\section{Introducción}

Raúl Zibechi (Montevideo, 1952) en las últimas dos décadas ha recorrido América Latina investigando, acompañando luchas populares y creando una de las más originales interpretaciones de los movimientos sociales, en diálogo crítico con las tradiciones de pensamiento que guían la praxis de los actores y las teorías que dominan el campo académico. Su punto de partida son los momentos insurreccionales, en los que inmensas movilizaciones desbordan las instituciones y despliegan otras formas de relacionarse invisibilizadas en la cotidianidad de la dominación.

La insurrección del 19 y 20 de diciembre de 2001 en Argentina lo conduce a una inmersión en los movimientos sociales posdictadura, Madres de Plaza de Mayo, Hijos e Hijas por la Identidad y la Justicia contra el Olvido y el Silencio (Hijos), movimiento estudiantil, radios comunitarias y piqueteros (Zibechi, 2003). Asimismo, la guerra del agua en Cochabamba, las movilizaciones en el altiplano boliviano - abril y septiembre de 2000y la insurrección en El Alto -octubre de 2003- le plantean la necesidad de reconstruir el poblamiento de la ciudad aymara (Zibechi, 2006). También ha captado su interés el movimiento zapatista, las comunidades de las periferias urbanas, el Movimiento Sin Tierra en Brasil y la Central de Cooperativas de Servicios Sociales de Lara (Cecosesola) en Venezuela, entre otros (Zibechi, 2015).

Comprender los fenómenos insurreccionales que, en su perspectiva, carecen de un centro director y no son producto de una convocatoria lleva al pensador uruguayo a descubrir la infraestructura que sustenta las movilizaciones, formada por redes de relaciones sociales de la vida cotidiana más que por organizaciones creadas para promover la acción colectiva. Estos vínculos, que denomina comunidades y sociedades en movimiento, crean otros mundos, poderes no estatales y formas de producción no capitalistas. Su contribución se inscribe así en una corriente que enfatiza la autonomía de los movimientos sociales frente al Estado, inspirada en las dinámicas anteriores a los denominados gobiernos progresistas (Holloway, 2002). Así pues, la contribución de Zibechi es muy relevante, tanto para comprender los desafíos prácticos que han enfrentado los movimientos sociales en dicho contexto como para vislumbrar las formas en que, a partir de estudios de caso en la región, se crean corpus teóricos que dialogan críticamente con las teorías producidas en otros contextos. 
Este artículo reconstruye críticamente los conceptos nodales de la interpretación propuesta por Zibechi. Las categorías de comunidad, autonomía, poderes no-estatales y las preguntas que plantea son cardinales para pensar la emancipación y la descolonización más allá del Estado. Sin embargo, la visión idealizada de la comunidad, la reducción del Estado a un aparato burocrático jerárquico y la imprecisión del concepto de movimiento social plantean problemas para analizar sus mutuas relaciones, particularmente en el marco de los gobiernos progresistas.

\section{De movimientos sociales a sociedades en movimiento}

Zibechi (2003, p. 22) hace una crítica similar a la que Rosa Luxemburgo le hizo a Lenin, ${ }^{1}$ según la cual, los movimientos tradicionales reproducen la lógica jerárquica del Estado: privilegian el crecimiento hacia fuera, la representación, la división formal del trabajo y los resultados. Así, crean una instancia especializada en mandar separada de sus bases, la cual anula sus potencialidades emancipatorias al subordinar a una táctica centralizada las luchas que no obedecen al fin prefijado de la toma del poder estatal.

En contraste, Zibechi reivindica las luchas espontáneas, no orientadas [178] por un fin predeterminado ni una organización jerárquica, como las que encuentra en las redes de sociabilidad popular en la Argentina de la década de 1990, agenciadas por una generación ajena a las instituciones disciplinarias de la sociedad industrial, que prefiere organizaciones flexibles e informales (Zibechi, 2003, pp. 27-30). Los nuevos movimientos se organizan en red y no reproducen la lógica estatal que crea un cuerpo funcionarial encargado de la dirección, privilegian el crecimiento hacia adentro - la creación de vínculos afectivos entre sus integrantes-, pues se conciben como fines en sí mismos, parte del nuevo mundo en el presente, y no como medios para la toma del poder y la construcción de ese mundo en el futuro (Zibechi, 2003, p. 138).

\footnotetext{
${ }^{1}$ En la polémica de 1904, Luxemburgo (1969) atacó la concepción jerárquica del partido defendida por Lenin. Mientras para este los obreros no desarrollan la conciencia de clase por sí mismos, sino que la reciben de fuera gracias a los revolucionarios profesionales, Luxemburgo planteó que la conciencia se desarrolla en la lucha misma y, por tanto, no es necesario adoptar una organización que separe verticalmente las bases de la dirigencia. Para Luxemburgo, esta última es la forma de organización propia de los ejércitos y de la industria, los cuales imponen una disciplina desde fuera. La emancipación requiere una autodisciplina muy distinta.
} 
En su trabajo sobre Argentina, Zibechi (2003, pp. 24-26 y p. 89) adopta categorías de las teorías de movilización de recursos y del proceso político, enfoques dominantes sobre los movimientos sociales, como repertorios de acción y estructura de oportunidades políticas. Sin embargo, el énfasis en lo afectivo y la concepción de los movimientos como fines en sí mismos le permitió cuestionar la explicación de la acción colectiva como producto de la racionalidad instrumental, la cual constituye otro de los marcos hegemónicos. Para Mancur Olson (1992), defensor de este enfoque, la acción colectiva se explica como un subproducto del cálculo individual de costo y beneficio, y los incentivos que crean las organizaciones para promoverla. Zibechi (2003, p. 187) muestra que esa lógica no explica las insurrecciones, donde no existen organizaciones que provean incentivos y los costos de la acción son superiores a los beneficios. En lugar de suponer individuos preexistentes a las relaciones sociales, su enfoque resalta que están insertos en comunidades cara a cara, con fuertes lazos afectivos que soportan la acción colectiva.

En su autocrítica, tres lustros después, Zibechi (2017, p. 63) se distancia más de las teorías dominantes. A partir de sus estudios con pueblos indígenas y pobladores de las periferias urbanas, interpreta las formas organizativas tradicionales como imposiciones coloniales. Por ejemplo, la cultura revolucionaria del Norte global percibe la familia y el campesinado como símbolos negativos del pasado. De ahí que privilegie como sujeto revolucionario un obrero extraído de la familia, haciendo de la filiación a la organización revolucionaria un hecho individual. Por el contrario, en los movimientos del Sur global la familia sigue siendo una estructura fundamental (Zibechi, 2015, p. 27).

Zibechi (2017, p. 13) incluso argumenta que el concepto de movimiento social no debe asumirse para explicar la acción colectiva en Latinoamérica. En particular, cuestiona un supuesto de teorías europeas y norteamericanas, según el cual los movimientos sociales se producen en «una sociedad unificada, con un Estado, una justicia, un sistema político». Al contrario, dice, debido a la dominación colonial, «en América Latina no puede hablarse de una sola sociedad, sino de sociedades que se dan a un tiempo como zonas de penumbras y contornos porosos cuyas fronteras e identidades o bien son resbaladizas o bien no existen» (Zibechi, 2015, pp. 58-59). De un lado, la «sociedad oficial, hegemónica, de herencia colonial con sus instituciones»; del otro, una sociedad con formas organizativas 
propias y relaciones sociales no capitalistas, formada por los excluidos de la sociedad hegemónica, que únicamente puede verse cuando se mueve, porque «no se organiza en torno a instituciones estatales». Por eso, prefiere denominar su acción «sociedad otra en movimiento».

Este concepto, sin embargo, no aclara por qué la categoría de movimiento social es inapropiada, no establece criterios para determinar cuándo existe una o varias sociedades, ni por qué las sociedades del Norte global se perciben como unificadas y democráticas, mientras las del Sur se conciben como un conjunto de sociedades traslapadas, como si los clivajes de sexo-género, etnia y clase fueran privativos del Sur. Zibechi (2015, p. 27) afirma que los pobres del mundo viven en «el reino del valor de uso, que queda por fuera del mercado». Parece retomar el dualismo estructural que concebía las sociedades latinoamericanas como formadas, por un lado, de relaciones sociales modernas y capitalistas, y por el otro, de una parte no capitalista excluida de los circuitos de la sociedad hegemónica (Cardoso y Faletto, 1969, pp. 11-12). Asume que existe un ámbito no tocado por el capitalismo, supuesto muy problemático en un mundo globalizado bajo la hegemonía capitalista (Negri y Hardt, 2001).

[180] Resulta también problemática la distinción entre movimientos de herencia colonial —como los sindicatos- y descolonizadores — basados en la comunidad-. Zibechi supone que los sindicatos no tuvieron una especificidad en Latinoamérica, sino que se acoplaron completamente al molde colonial, y no lo demuestra empíricamente; además, se limita a una visión de los movimientos sociales como agentes progresistas. En esto coincide con perspectivas como la de Alain Touraine (1987), quien concibe los movimientos como acciones de una clase en la disputa por la historicidad o el sentido de lo societal y, por consiguiente, como necesariamente progresistas. Por eso distinguía entre movimientos y contramovimientos. Empero, privilegiar la ideología como el elemento que define el movimiento omite formas de acción colectiva que reúnen características sociológicas para concebirse como movimientos sociales, pero no apuestan por el cambio social en sentido emancipatorio.

A nivel analítico, existen varios aspectos problemáticos. Para Zibechi (2006, p. 124) las teorías dominantes únicamente entienden como movimientos sociales los que adoptan formas «institucionalizadas», con objetivos definidos y una organización distinta a la que preexiste en la 
vida cotidiana. Considera restringido ese criterio, pues en Latinoamérica los movimientos asumen formas no institucionalizadas (Zibechi, 2008, p. 48). Este concepto de institucionalización es problemático, mantiene cierta resonancia de enfoques funcionalistas como el de Neil Smelser (1995), quien concibe los movimientos como resultado de situaciones no institucionalizadas, en las cuales se fracturan las normas o valores del sistema social.

En Zibechi (2006, p. 107) lo institucional se confunde con todo aquello que implique jerarquía, organización o siga la lógica vertical y representativa del Estado. Así, divide los movimientos en institucionalizados y no institucionalizados, cuando en realidad las organizaciones de los movimientos tienen siempre distintos grados de institucionalización en su sentido más amplio: patrones regulares que permiten identificar una relación social (March y Olsen, 1997). Así, habría que matizar el grado en que las insurrecciones disuelven las instituciones en favor de las relaciones sociales comunitarias — como afirma Zibechi (2006, p. 33)—, pues es precisamente la regularidad de las relaciones sociales cotidianas en las comunidades -rotación de cargos y trabajos, asambleas, entre otros- la que sostiene las movilizaciones. Disolver las instituciones supondría introducir una imprevisibilidad ilimitada que haría imposible la vida social. Por tanto, toda acción colectiva requiere algún tipo de institucionalidad.

Por otra parte, no parece acertado afirmar que las teorías dominantes únicamente son idóneas para estudiar movimientos «institucionalizados» o con organizaciones formales. Alberto Melucci (1999) resaltó el papel de las redes de relaciones sociales de la vida cotidiana como el lugar en donde se forja la identidad colectiva y el potencial de movilización. Pero incluso en el enfoque de síntesis dominante (McAdam, Tarrow y Tilly, 2005; Tarrow, 1997), el concepto de estructuras de movilización designa los canales colectivos formales e informales mediante los cuales las personas se vinculan a la acción colectiva (McAdam, McCarthy y Zald, 1999, p. 25). Es decir, un movimiento social es un tipo particular de acción colectiva y puede vincular distintas formas organizativas (McCarthy, 1999, p. 206).

Las organizaciones del movimiento social propiamente dichas tienen como finalidad promover la acción colectiva y pueden tener distintos grados de formalización y profesionalización; pero, además, en un movimiento participan otras formas organizativas con finalidades propias, formales - 
como los partidos, los gremios, los sindicatos o las ONG- e informales - como los grupos de amigos, la familia, los vecinos u otras redes de relaciones sociales de la vida cotidiana-. Por esa razón, el éxito de una movilización necesariamente implica el desborde de las organizaciones de los movimientos, supone movilizar las redes de relaciones sociales, grupos u organizaciones cuyo fin no es la acción colectiva.

De fondo, la categoría de movimiento social que utiliza Zibechi es imprecisa. Aunque explícitamente afirma que su interés es el estudio de la acción, el «mover-se» (Zibechi 2008, p. 52), cuando analiza los movimientos tradicionales confunde el movimiento con la organización - sindicato, partido- y cuando estudia los nuevos movimientos lo hace con las comunidades. Varios de los casos que estudia difícilmente pueden concebirse como movimientos sociales, entendidos como un tipo particular de acción colectiva. ${ }^{2}$ Los acueductos comunitarios en Colombia, las fábricas recuperadas en Argentina o la cooperativa Cecosesola en Venezuela (Zibechi, 2017, p. 15) son formas de acción colectiva pero no necesariamente movimientos, pueden ser parte de un movimiento social, junto con otras formas organizativas, pero no se las puede confundir con el movimiento mismo.

\section{Comunidad y poderes no-estatales}

Según Zibechi (2003, pp. 140-143), en los movimientos basados en comunidades el «poder como dominación» es limitado, tanto por el funcionamiento colectivo como por los intensos lazos afectivos entre sus integrantes, y predomina el «poder como capacidad». La comunidad es un poder no-estatal, donde se practica la reciprocidad, la asamblea, la rotación de tareas y el «mandar obedeciendo» de los zapatistas (Zibechi, 2015, pp. 189-190), lo cual limitan la competencia y la disputa por el poder, ligadas a lo «masculino», primando una lógica femenina del cuidado familiar extendido, como en los comedores populares de Lima (Zibechi, 2008, p. 95).

\footnotetext{
${ }^{2}$ Por ejemplo, Charles Tilly y Lesly Wood (2010, p. 22) enfatizan la acción colectiva sobre la organización, los repertorios o la ideología en su concepción de movimiento social como una combinación de: a) campañas — esfuerzos públicos, organizados y sostenidos por trasladar a las autoridades pertinentes las reivindicaciones colectivas-; b) repertorios —el uso combinado de ciertas formas de acción política, como coaliciones y asociaciones, reuniones, manifestaciones-; y c) demostraciones públicas y concertadas de valor, unidad, número y compromiso.
} 
Las comunidades se basan en la participación de todos sus miembros. Para Zibechi (2010, p. 110), la representación excluye a los representados, convirtiéndolos en agentes pasivos. Este rasgo contrapone la comunidad al Estado y a la organización jerárquica del capitalismo. A diferencia de los ciudadanos y consumidores, los miembros de una comunidad no son representables, no pueden delegar su poder (Zibechi, 2003, p. 34). Por eso, en las comunidades no opera la lógica de mayorías y minorías propia de las elecciones sino el consenso como producción de relaciones sociales horizontales, recíprocas y afectivas (Zibechi, 2003, p. 59). Por ejemplo, en las comunidades vecinales de El Alto el desempeño de un cargo no es voluntario, no depende de elección ni de méritos, sino del turno obligatorio, entre las bases y quienes ocupan cargos existe un mandato imperativo, ambas cosas evitan el surgimiento de un poder separado y por encima de la comunidad (Zibechi, 2006, p. 40).

Los lazos afectivos comunitarios se crean en situaciones extremas en las que se enfrenta el dolor, no son instrumentales. Por ejemplo, en Argentina, comunidades como Madres de Plaza de Mayo o Hijos lucharon por reconstruir los vínculos sociales rotos por la dictadura; en El Alto, el desarraigo enfrenta a los migrantes a enormes privaciones, el dolor se convierte en elemento de unión (Zibechi, 2006, p. 56). Los lazos comunitarios permiten asumir la situación de exclusión ya no como carencia sino como posibilidad, «se emprende el camino de construir un mundo nuevo desde la diferencia» (Zibechi, 2003, p. 91).

En la comunidad la cualificación de esos lazos es más importante que los resultados externos, «el fin es el mismo grupo, la gente que lo compone» (Zibechi, 2003, p. 41). Para Zibechi (2003, p. 133), los lazos afectivos son un freno a la lógica instrumental que ve la comunidad como un medio. Aunque difícilmente se puede evitar y no siempre es negativa, su primacía es un obstáculo para la creación de vínculos comunitarios, porque convierte al otro en un adversario potencial en competencia y aumenta la probabilidad de cooptación de las comunidades por agentes externos como el Estado.

Como puede verse, Zibechi idealiza las comunidades, enfocándolas desde los principios más que desde las prácticas. La comunidad se concibe como todo lo contrario de la asociación, vista como un vínculo jerárquico, con una instancia especializada en mandar, donde el grupo es un instrumento para fines externos y las personas se asumen como medios 
y no como fines (Zibechi, 2006, p. 37). Por eso Zibechi (2008, p. 128) duda de que en una comunidad se pueda hablar de poder: «Las Juntas de Buen Gobierno en los municipios autónomos zapatistas, ejercen el poder de forma rotatoria de modo que en un tiempo todos los habitantes de una zona han aprendido a gobernar. Pero, ipuede hablarse de poder cuando lo ejerce la comunidad?». Su énfasis en el «poder como capacidad» desconoce que en toda relación social, incluso basada en afectos, existe «poder como dominación». El consenso comunitario, construido a partir de fuertes lazos afectivos, se ofrece como el factor que debilita este poder (Zibechi, 2003, p. 40), empero, no analiza la forma como este poder obstaculiza el consenso. Por ejemplo, respecto a Madres de Plaza de Mayo, admite que hubo una ruptura del consenso, pero omite su análisis (Zibechi, 2003, p. 50).

Dado el predominio del colectivo sobre el individuo, cabe preguntar qué tan emancipatorio es el vínculo comunitario. Para Zibechi (2010, p. $110)$, en los «territorios en resistencia» los individuos se disuelven porque no pueden garantizar la sobrevivencia y se recurre cotidianamente a la comunidad. Reconoce que en las comunidades se practican ciertos tipos de autoritarismo. Por ejemplo, las comunidades vecinales en El Alto son propietarias y gestoras de los recursos de educación, territorio y comercio, condicionando el acceso a la lealtad individual (Zibechi, 2006, p. 56). No obstante, no extrae las consecuencias que este tipo de prácticas tiene para su concepción de la comunidad y la emancipación, aunque resalta que en las comunidades las opresiones no se ocultan sino se trabajan (Zibechi, 2015, p. 191).

Por otra parte, la potencia emancipatoria de las comunidades depende de su capacidad para constituirse en poderes no-estatales, "poderes no separados, no escindidos de la sociedad, que no forman un cuadro aparte, ni para tomar decisiones, ni para luchar, ni para resolver conflictos internos» (Zibechi, 2006, p. 29), como las juntas zapatistas de buen gobierno o las comunidades vecinales de El Alto. Zibechi $(2015$, p. 26) ve en estos poderes una posibilidad para salir del círculo vicioso en que han caído los procesos revolucionarios que toman el Estado para reproducir la dominación: «el Estado es una relación colonial-capitalista que no puede ser desmontada desde su interior».

Sin embargo, Zibechi es ambiguo, unas veces afirma que los poderes no-estatales tienen una existencia potencial, solo emergen en momentos 
de insurrección, mientras otras veces supone su existencia efectiva. En las insurrecciones de El Alto en 2003 emergen poderes que dispersan el Estado porque las tareas de la movilización no se distinguen de la vida cotidiana, hay una división mínima del trabajo y sus procedimientos rotación de cargos, asambleas, entre otros- impiden la formación de un cuerpo especializado en mandar (Zibechi, 2006, pp. 35-36). Así, lo que está en potencia en la comunidad irrumpe efectivamente en situaciones excepcionales de insurrección, por tanto, los movimientos sociales pueden crear poderes no-estatales a partir de las potencias de sus comunidades, pero eso no necesariamente implica que lo hagan (Zibechi, 2017, p. 76). De ahí la dificultad para analizar las relaciones entre poderes no-estatales y Estado, pues el potencial poder no-estatal y el efectivo poder estatal coexisten en los mismos espacio-tiempos en tensión: «no existen sociedades ni espacios sociales sin Estado: cuando hablamos de poderes no estatales nos estamos refiriendo a su capacidad de dispersar el Estado o impedir que cristalice» (Zibechi, 2006, p. 103). Por ejemplo, en las comunidades aymara, si bien existe autogobierno, el clientelismo estatal opera en su interior (Zibechi, 2006, p. 190).

No obstante, en general Zibechi da por sentado la existencia efectiva, no potencial, de poderes no-estatales, identificándolos con los vínculos comunitarios permanentes, no solo durante el momento insurreccional, incluso arguye que tales poderes anulan la discusión sobre la «transición» —cara al marxismo-y la «prefiguración», no prefiguran una sociedad futura, «son, de hecho, la sociedad otra realmente posible» (Zibechi, 2015, p. 24). Esta ambigüedad entre lo potencial y lo efectivo es reconocida por el propio autor: "Quiero decir que ese "mundo otro" no existe, pero existe a la vez en forma de prácticas más o menos extensas y permanentes» (Zibechi, 2017, p. 78).

Un problema analítico es la concepción del Estado que sostiene esta argumentación, puesto que lo reduce a un aparato burocrático. ${ }^{3}$ Por eso Zibechi (2006, p. 47) ve como un «cambio estructural positivo» el que la población pobre latinoamericana esté al margen del Estado, porque a

\footnotetext{
${ }^{3}$ La discusión sobre las dimensiones simbólicas y el carácter de relación social del Estado, más que reducir su comprensión a un aparato burocrático, desborda este trabajo; sin embargo, incluso en perspectivas marxistas que ven el Estado como un «instrumento» al servicio de la clase dominante, nunca se reduce a su faceta de aparato burocrático, sino que depende de las luchas de clase. Una síntesis de estas discusiones en Bob Jessop (1999, pp. 99-126).
} 
diferencia de la clase obrera, la cual operaba dentro del Estado en partidos y sindicatos, los movimiento hoy pueden operar fuera, autónomamente, de ahí también que conciba el poder no-estatal como aquel que no crea una instancia-burocracia separada de la comunidad, especializada en mandar. No obstante, la inexistencia de tal aparato no es suficiente para determinar la existencia de poderes no estatales. En el interior de la comunidad existen relaciones de poder desiguales, de sexo-género, etarias e incluso clasistas, que en una perspectiva micropolítica como la de Michel Foucault (1991) tienen un principio articulador en el Estado; además, la primacía de lo colectivo sobre lo individual cuestiona la inexistencia de poder estatal, porque existe un "consenso» que fundamenta la obligación política, así sea informal y la coerción sea ejercida por toda la comunidad y no por una burocracia especializada (Zibechi, 2015, p. 191).

Esa reducción del Estado a aparato burocrático plantea grandes problemas para examinar qué tipo de relaciones establece con los poderes no-estatales. Hipotéticamente, existen varias posibilidades de poderes noestatales: lo antiestatal, lo contraestatal y lo paraestatal. Un poder que no emula la «lógica» del Estado - un aparato especializado en mandar al margen de la comunidad - no necesariamente es un poder antiestatal, lo que supondría no ser funcional al Estado ni aspirar a convertirse en Estado; un poder contraestatal se opone a un Estado en particular, pero no necesariamente al Estado como forma política e incluso puede pretender devenir Estado; en fin, un poder no-estatal puede configurarse como paraestatal si coincide con las normas o valores que sustentan el Estado.

Sin embargo, Zibechi no hace distinciones. Por ejemplo, sobre la justicia en las comunidades de El Alto afirma: «no pretendo juzgar la justicia comunitaria [...] sino constatar que en el mundo aymara existen formas de justicia no estatales» (Zibechi, 2006, p. 136). Esta justicia ejercida por la comunidad, que no acude al Estado porque no encuentra garantías para sancionar y restablecer las relaciones comunitarias, trata de reintegrar a quienes incurren en alguna falta, pero muchas veces aplica la pena de muerte. Es no-estatal, no la ejerce el Estado ni una instancia especializada en castigar, pero eso no la hace menos funcional a la dominación estatal. Estrictamente, es paraestatal porque hace la tarea del Estado y se apoya en los mismos valores: defensa de la propiedad privada, ataque a lo que amenaza el orden, entre otros. Un análisis detallado cabría realizar para otros ejemplos de poderes no-estatales (Zibechi, 2017, pp. 95-96), como la 
guardia indígena del Cauca en Colombia, las rondas campesinas en Perú o las autodefensas de Guerrero en México, poderes no-estatales que no siempre dejan de ser funcionales al Estado.

Finalmente, la reducción del Estado a un aparato y una lógica jerárquica olvida las transformaciones que ha sufrido desde el periodo neoliberal en Latinoamérica. Las reformas recomendadas por los organismos multilaterales — promoción de la participación ciudadana, descentralización, fortalecimiento de la sociedad civil- abandonaron los enfoques verticales de la gestión pública. Los movimientos y organizaciones sociales empezaron a verse como agentes funcionales y aliados del Estado para conseguir la «gobernanza» (Aguilar, 2008).

\section{Autonomía y emancipación}

La autonomía «es parte del proceso de emancipación en el que se cuestiona el lugar heredado en la sociedad» (Zibechi, 2006, p. 176). Zibechi arriba a este concepto examinando los proyectos de autogestión de los piqueteros, en los que deconstruyen prácticamente el lugar que les asigna el sistema, como marginales y desempleados, para «empezar a crear otra vida en esta vida» (Zibechi, 2003, p. 131). Implica una acción «autoafirmativa» que no responde a la agenda establecida desde arriba, como lo hacía el sindicato, porque «decir que no, a cada cosa que nos dice el amo, no nos mueve un pelo del lugar de esclavos» (Zibechi, 2003, p. 112).

La autonomía también está comprendida en un proceso descolonizador. Basado en Frantz Fanon, Zibechi sostiene que en la «zona del ser» es posible la autonomía individual y social; en la zona del «no ser», por el contrario, no hay lugar para la autonomía dentro de la sociedad dominante, porque la violencia contra los dominados es la norma y no la excepción. En consecuencia, es necesario crear un espacio propio, que resguarde el proyecto alternativo de sociedad (Zibechi, 2015, pp. 23-24). Además, parte de la dominación colonial está sustentada en que el modo de ser del colonizador se establece como objeto de deseo del colonizado. La autonomía permite que el colonizado deje de desear el mundo del colonizador y se autoafirme en un mundo propio, impide que la descolonización se limite a «ser como ellos» y se convierta en una nueva relación de dominación, donde el colonizado ocupa el lugar del colonizador (Zibechi, 2015, pp. 38-39). 
Se trata de una concepción del cambio social que no pasa por la toma del poder estatal ni por un periodo de «transición». La emancipación no puede conseguirse si los dominados se organizan como los dominadores, en un Estado. Zibechi sigue la reflexión de Karl Marx sobre la Comuna de París de 1871: el acontecimiento revolucionario no es el punto de partida para la creación del mundo otro, sino apenas «un breve jalón» a un proceso de gestación muy anterior, "da suelta», permite que salgan a flote los vínculos de la sociedad otra que ya existe en la vida cotidiana de los dominados (Zibechi, 2006, pp. 23-24). Por tanto, la autonomía es un fin en sí misma, no un medio para construir otro mundo en el futuro, sino parte del otro mundo en el presente (Zibechi, 2003, p. 49). El cambio social parte de lo local y la autonomía resguarda las prácticas que lo propician.

Precisamente, una crítica señala que las formas de vida comunitarias solo pueden funcionar en pequeña escala y no son una alternativa en el ámbito global. Para Zibechi (2015, p. 192) este argumento pasa por alto que las prácticas emancipatorias siempre se realizan en espacios concretos, en consecuencia, la emancipación implica crear espacios que contrarresten las relaciones sociales hegemónicas; además, esa crítica supone que la transición hacia una sociedad otra tendrá que gestionar los bienes comunes

en el ámbito planetario, eso necesariamente implicaría una transición orientada por el Estado, pero las transiciones sociales de larga duración, del feudalismo al capitalismo, por ejemplo, muestran un desarrollo caótico antes que dirigido (Zibechi, 2015, p. 193). Así, una transición dirigida no solo es indeseable, porque supone afirmar el Estado, sino improbable.

El cambio social desde abajo implica una lucha hegemónica, más que un tránsito súbito, que empieza en las comunidades por la afirmación de la cultura popular, base de la autonomía. Según Zibechi (2003, p. 46), si no existiera una cultura propia en los sectores populares, si estuvieran totalmente alienados por la cultura dominante, no habría posibilidad de emancipación. Por eso critica la perspectiva leninista, para la cual los obreros no pueden emanciparse por sí solos y necesitan de los revolucionarios profesionales, omitiendo que emancipación es necesariamente autoemancipación. En la cultura popular coexisten elementos de la cultura opresora y elementos liberadores, la emancipación pasa por potenciar estos y limitar aquellos (Zibechi, 2003, p. 43). 
Pero la autonomía también implica alternativas a las formas de consumo y producción capitalistas, por ejemplo; las mujeres que agencian comedores comunitarios en las periferias de Lima no producen para el mercado, puesto que sus beneficiarios son personas de la misma comunidad y menos de $10 \%$ de su producción se vende, por tanto, producen «no-mercancías», sustraídas a la circulación como valor de cambio (Zibechi, 2008, p. 94); una panadería comunitaria en Barracas, Buenos Aires, tampoco realiza sus productos en el mercado, pues tiene $80 \%$ de clientes fijos, quienes se implican en las actividades de la comunidad. Mediante la rotación de tareas, en estos emprendimientos los distintos trabajos dejan de ser equivalentes, ya no se trata de trabajo abstracto en función del tiempo sino de un trabajo «útil y concreto» (Zibechi, 2008, p. 116-117); además, el productor se apropia de los conocimientos necesarios para producir en su totalidad un producto, a diferencia de lo que sucede en la cadena de montaje taylorista, que enajena ese saber y ahonda la separación entre productor y producto. En consecuencia, no existe jerarquía entre circulación y producción, trabajos productivos e improductivos: se producen relaciones sociales no capitalistas y el trabajador deja de ser un apéndice de la maquinaria física y social de la industria.

Estos argumentos, sin embargo, presentan aspectos discutibles. Zibechi olvida la vieja polémica que, desde André Gunder Frank a finales de la década de 1960, se ha producido en Latinoamérica sobre el modo de producción y, particularmente, si en el mundo globalizado existen ámbitos no capitalistas. Sostiene que sí existen, en las experiencias productivas de los movimientos, en pugna con las relaciones sociales capitalistas, pero sus postulados están basados en el análisis de una configuración particular del modo de producción: el capitalismo fordista-taylorista (Zibechi, 2006, p. 69). Esa fase se caracterizó por el predominio de estructuras jerárquicas en la relación capital-trabajo, la división y especialización laboral que privan al obrero del conocimiento del ciclo productivo y la aspiración al pleno empleo: el salario como anticipación de la adquisición y realización de las mercancías. Desde esta perspectiva, los ejemplos de Zibechi consiguen sustraerse a la lógica capitalista.

No obstante, sus argumentos pierden efectividad si se acepta que hoy existe otra configuración en el modo de producción: el posfordismo. De acuerdo con Antonio Negri y Michael Hardt $(2001 ;$ 2004), para tomar 
un ejemplo cercano a Zibechi, en este escenario el capitalismo vive de la producción y reproducción de la vida social. La producción se ha descentralizado y desterritorializado gracias a la informatización y a la automatización que permiten ejercer controles a larga distancia y en tiempo real. Entre otras cosas, esto ha desdibujado el límite entre tiempo de trabajo y tiempo de ocio. Dado que la vida en su totalidad —lenguaje, pensamiento, capacidad de crear afectos y relaciones sociales- es lo que hoy se explota, la teoría del valor-trabajo ha entrado en crisis, el tiempo ha dejado de ser un indicador del valor. Las relaciones laborales, lejos de la división del trabajo y la especialización tayloristas, hoy se confunden con los espacios y tiempos de la vida privada, la fábrica o la oficina se confunden con el hogar y cada vez es más difícil dejar de producir, desconectarse del trabajo.

La propiedad privada, incluso, presenta transformaciones considerables. Las inversiones son cada vez menos en activos fijos y más en relaciones contractuales que, sin otorgar propiedad, garantizan el acceso a bienes y servicios, pues los activos fijos se convierten en una carga en momentos de crisis mientras el capital líquido puede migrar con facilidad (Rifkin, 2014). Por otro lado, la ideología hegemónica del éxito profesional está sustentada en la creación de fuertes relaciones afectivas entre trabajadores, estimula la proactividad y el emprendimiento, el liderazgo colectivo y horizontal, y el cultivo de la autonomía en un contexto de flexibilización y precarización laboral (Marzano, 2011). Así, es muy complicado determinar que existan espacios fuera del sistema capitalista y más bien habría que preguntarse si los emprendimientos y la autonomía que reivindican los movimientos sociales son funcionales al capitalismo en su fase actual. Habría que analizar las experiencias que trabaja Zibechi bajo las nuevas formas de control, más que oponerlas a una forma de capitalismo ya caduca, el fordismo-taylorismo.

\section{El desafío de los gobiernos progresistas}

Según Zibechi (2015, p. 65), los gobiernos progresistas evidencian que la izquierda «no entendió que el Estado no puede ser refundado», no fueron un retorno al populismo ni a la socialdemocracia, sino una alianza entre capitalistas y administradores estatales, estos ofrecieron seguridad jurídica y contención del conflicto, aquellos inversión y respeto a las reglas de juego bajo el mismo modelo neoliberal extractivista (Zibechi, 2010, p. 92). Estos gobiernos diluyen el conflicto, las políticas sociales 
funcionan como dispositivos de control sobre los movimientos y las clases dominantes consienten ser conducidas políticamente por los dominados, mientras no cuestionen la explotación capitalista y sus privilegios, configurando una "hegemonía al revés», concepto que Zibechi (2015, p. 167) adopta del pensador brasileño Francisco de Oliveira.

La política social, la militarización y criminalización de la pobreza y los pobres en las periferias urbanas, donde han emergido los desafíos más relevantes al sistema desde el Caracazo (1989), son los principales instrumentos de disciplinamiento de estos gobiernos (Zibechi, 2008, p. 22). El capitalismo contemporáneo no tiene otro modo de hacer frente a la pobreza, que ha dejado de ser un fenómeno residual y ya no depende de la economía nacional (Zibechi, 2008, pp. 39-40). La economía extractivista basada en la minería y los agronegocios necesita políticas sociales, porque ocupa muy poca mano de obra y no produce consumo local.

Según Zibechi (2010, p. 22), las políticas sociales contrarrestan las formas de vida no capitalista que se ingenian los de abajo, son calcadas del combate a la pobreza ideado por el Banco Mundial tras la derrota de Estados Unidos en Vietnam - asistencialistas y focalizadas-, no contemplan cambios estructurales, responden a las formas comunitarias de los movimientos pero se diseñan sin participación ciudadana, a pesar de enarbolar la autonomía de la «sociedad civil» (Zibechi 2010, pp. 124-125). El Banco Mundial se apropió los conceptos de los movimientos —buen vivir, descolonización, lucha contra el patriarcado-, construyendo una retórica tecnocrática utilizada en los gobiernos progresistas por la élite procedente de la academia y las ONG (Zibechi 2015, p. 273). Eso se explica porque los movimientos comunitarios no pueden ser derrotados mediante la represión, excepto por exterminio generalizado. Su derrota procede desde la misma izquierda, de las ONG, los partidos y el propio Estado, que los neutralizan vía cooptación (Zibechi, 2008, p. 84). Por eso, las políticas sociales anatemizan el conflicto, inadmisible para gestionar cualquier cosa con el Estado, presentado como aliado y no como antagonista, y despolitizan la población apelando a la «sociedad civil» (Zibechi, 2010, pp. 97-98).

Para penetrar en los territorios el Estado requiere un interlocutor, para construirlo trata de convertir los movimientos en organizaciones sociales tipo ONG. Los movimientos sufren una institucionalización, debilitan sus prácticas horizontales, establecen una división del trabajo jerárquica, 
pierden autonomía y su potencial emancipatorio se ve neutralizado o instrumentalizado al servicio de la gobernabilidad (Zibechi, 2010, pp. 9394). Pasan a formar una red territorial, un «nuevo panóptico» que permite observar todo lo que sucede con los pobres, una forma de control inmanente, ya no exterior a los activistas sino agenciado por ellos mismos (Zibechi, 2010, pp. 103-105). En fin, los emprendimientos que promueve el Estado no solo acaban con la autonomía, sino que fragmentan los movimientos en una infinidad de identidades — mujeres, jóvenes, adultos mayores, entre otros-.

Las críticas de Zibechi son precisas y originales, pero sus concepciones de Estado y movimiento social impiden captar con mayor complejidad la relación entre ambos. En su autocrítica, Zibechi (2017, pp. 38-39) afirma que «la forma como la mayoría abrumadora de movimientos se plegaron a los gobiernos progresistas, revela debilidades intrínsecas en ellos». Este diagnóstico está necesariamente ligado a su perspectiva esencialista del Estado, concebido como el «mal», fundamentalmente jerárquico y burocratizado, y de los movimientos como intrínsecamente progresistas, lo que impide captar la diversidad de relaciones que los actores sociales pueden establecer con los organismos y formas de acción estatales.

[192] El rechazo de Zibechi a todo lo relacionado con el Estado es ideológico. Sostiene que las transformaciones que requieren los sectores populares no pueden obtenerse mediante el Estado, no se puede construir otro mundo mediante la toma del poder estatal: «Ésa es una nueva ley de hierro de las revoluciones, avalada por todo un siglo de experiencias nefastas» (Zibechi, 2003, p. 202). Esta proposición, sin embargo, incurre en cierto anacronismo, pues no tiene en cuenta las alternativas concretas que enfrentaron los procesos revolucionarios del siglo xx y omite cualquier matiz en una lógica del todo o nada. Pero sobre todo no hay manera de probar qué alternativas distintas a la toma del poder estatal hubieran sido exitosas en la construcción del hipotético mundo otro.

Sin embargo, basado en ese postulado, Zibechi aplica un doble racero: analiza los movimientos desde el punto de vista de las potencias mientras que el Estado solo se ve desde la perspectiva de los límites. Potencias y límites configuran dos formas de hacer política: «Instalarse en las limitaciones es poner en primer plano lo que los movimientos se han visto incapaces de hacer» (Zibechi, 2006, p. 27). Según el autor, la política con base en los límites termina por suplantar el sujeto de los cambios, que ya no es la 
sociedad en movimiento sino el partido o el Estado. Así, mientras el Estado es visto como un ente monolítico, el análisis de las potencias emancipatorias de los movimientos es rico en matices. Aunque las interpretaciones de Zibechi se enriquecen a la luz de nuevas experiencias, ese doble racero se mantiene. Por ejemplo, en un análisis reciente deja abierta la pregunta por si los movimientos basados en comunidades pueden constituirse en un paradigma de oposición, dado que sus formas de operación, por el hecho de ser participativas y no delegar la toma de decisión, se hacen muy lentas y solo son posibles en pequeños grupos, cuyos vínculos sean fuertes; sin embargo, al mismo tiempo hace un Ilamado a no exigir más de lo que han conseguido (Zibechi, 2015, p. 48).

En cambio, su evaluación de los gobiernos progresistas es unidireccional. Considera que no hubo una «refundación» del Estado, «más allá de algunos cambios cosméticos (como colocarle el nombre "plurinacional" a las viejas instituciones heredadas de la colonia o crear nuevas reparticiones dentro de la misma lógica estatista) todo quedó en su lugar, aunque en despachos ministeriales y parlamentos aparecieron ponchos y polleras y se pronunciaron lenguas originarias» (Machado y Zibechi, 2016, p. 15). Sin abordar la discusión sobre la «refundación», esta afirmación evidencia una comprensión limitada del Estado y del problema nacional en Bolivia y Ecuador. El reconocimiento de distintas nacionalidades, ruptura radical con el imaginario de nación mestiza que se estableció desde la fundación de la república, es reducido a cambio "cosmético». La ley constitucional queda reducida a pura formalidad sin consecuencias fácticas ni simbólicas.

Por otra parte, las limitaciones en el análisis de la relación entre movimientos sociales y Estado se explican por la confusión entre movimientos y organizaciones sociales. Al no distinguir entre organizaciones sociales, organizaciones del movimiento social y otro tipo de redes de relaciones sociales, como anteriormente se argumentó, Zibechi incurre en imprecisiones. Cuando los Estados cooptan ciertas organizaciones no necesariamente cooptan al movimiento social. En los movimientos sociales, entendidos como un tipo específico de acción colectiva, participan redes de relaciones sociales, organizaciones formales o informales con distintos objetivos, incluso ONG y partidos políticos, por lo que decir que el Estado coopta a un movimiento cuando coopta una de estas organizaciones es analíticamente inexacto. 
Pero incluso cuando la cooptación se despliega sobre la organización del movimiento social, aquella cuyo fin es promover la movilización, las relaciones sociales de sus integrantes mantienen una potencialidad para producir acción colectiva. No es preciso decir que esas organizaciones perdieron su capacidad de movilizarse por recibir recursos o acatar orientaciones estatales (Zibechi, 2010, p. 97), por el contrario, mientras existan relaciones sociales es posible que de allí emerja la acción colectiva. En este sentido, el papel de las redes de relaciones sociales que sustentan un movimiento, configuren o no organizaciones formales, es análogo al de las formas de sociabilidad obrera en el análisis que de la formación del sujeto clase hizo Marx. ${ }^{4}$

Finalmente, con la idealización de la comunidad, Zibechi parece concebir los movimientos como actores unificados, perdiendo de vista las contiendas por el sentido que se producen en su interior. No existen relaciones sociales antiestatales o anticapitalistas en esencia, su orientación depende del sentido que a ellas se imprima, el cual está constantemente en disputa. Por ejemplo, en Colombia a finales de la década de 1960 el Gobierno creó la Asociación Nacional de Usuarios Campesinos como base de respaldo para la reforma agraria y para evitar que el campesinado fuera interpelado por el proyecto revolucionario, pero eso no evitó que, bajo el influjo de distintas corrientes de izquierda que disputaron su sentido, la organización se constituyera en el principal agente de contestación (Múnera, 1998).

\section{Conclusión}

La obra de Zibechi representa un gran esfuerzo por crear categorías analíticas a partir del estudio comprometido de distintos casos latinoamericanos, cuyo elemento articulador es la pregunta por el cambio social sin tomar el poder estatal. No obstante, los problemas conceptuales tienen tanto consecuencias analíticas como sobre las posibilidades liberadoras que designan.

\footnotetext{
${ }^{4}$ Marx (1985, pp. 216-217) concebía las relaciones regulares de los obreros en la fábrica como condición necesaria para su constitución en clase, por eso argumentó que el modo de vida de los campesinos franceses, que los distanciaba unos de otros impidiéndoles formar intereses comunes, imposibilitaba concebirlos como clase.
} 
El enfoque de Zibechi pone en cuestión supuestos de las teorías dominantes, como la explicación racional de la acción colectiva, al enfrentarlos a situaciones inéditas como las insurrecciones; no obstante, los problemas de conceptualización -la ausencia de una concepción de «sociedad», el limitado concepto de institucionalización, el supuesto de que las teorías dominantes solo son idóneas para estudiar movimientos institucionalizados y la reducción de los movimientos sociales a acciones con sentido progresista- dificultan el análisis. Zibechi identifica los movimientos sociales con organizaciones y comunidades, en lugar de concebirlos como un tipo particular de acción colectiva y asume que son esencialmente progresistas. Esta concepción plantea problemas para analizar las relaciones entre movimientos y Estado, sobre todo en la coyuntura de los gobiernos progresistas, dejando como única alternativa analítica la autonomía o la cooptación.

La comunidad, la autonomía y los poderes no-estatales nombran la posibilidad de una forma de emancipación que no pase por el Estado, sino por la creación de relaciones sociales alternativas a la lógica jerárquica y representativa, y de formas de consumo y producción contrarias a las hegemónicas; no obstante, la fundamentación de esas categorías pasa por alto que el poder como dominación es inmanente a las relaciones sociales y no existen relaciones en esencia no-estatales o anticapitalistas, sino que su sentido depende de la disputa permanente entre los agentes que de ellas participan. Con cierta idealización se resaltan las potencialidades de la comunidad, descuidando las formas de autoritarismo que anidan en su interior. La ambigüedad con que se formula el concepto de poder no-estatal plantea la necesidad de un análisis detallado que identifique la gama de relaciones que establece con el Estado, pues no todo poder no-estatal le es disfuncional.

Zibechi tiende a reducir el Estado a un aparato burocrático jerárquico pasando por alto dimensiones, su eficacia simbólica y su carácter de relación social, relevantes para pensar los poderes no-estatales y las potencialidades emancipatorias de las comunidades; además, ese concepto corresponde al Estado desarrollista anterior a las reformas neoliberales, de la misma manera que el capitalismo sobre el que basa sus argumentos corresponde al fordistataylorista. A consecuencia de la reestructuración neoliberal, anterior a los 
gobiernos progresistas, el Estado dejó de ser el agente predominante del cambio social, viéndose obligado a descentralizar, flexibilizar y coordinar su acción con otros actores, incluyendo movimientos sociales, y a adoptar un funcionamiento más complejo que la lógica burocrática jerárquica conceptualizada por Zibechi. Igualmente, la autogestión, el emprendimiento, la producción de no-mercancías o las relaciones de producción horizontales podrían concebirse como alternativas al capitalismo fordista-taylorista, pero, dado que coinciden con las prácticas funcionales al capitalismo posfordista, cabe preguntarse si hoy constituyen alternativas.

\section{Referencias bibliográficas}

1. Aguilar, Luís. (2008). Gobernanza y gestión pública. México, D. F.: FCE.

Cardoso, Fernando Henrique y Faletto, Enzo. (1969). Dependencia y desarrollo en América Latina. México, D. F.: Siglo xxı.

2. Foucault, Michel. (1991). El sujeto y el poder. Bogotá, D. C.: Carpe Diem.

3. Jessop, Bob. (1999). Crisis del Estado de Bienestar. Bogotá, D. C.: Siglo del Hombre.

4. Holloway, John. (2002). Cambiar el mundo sin tomar el poder. Barcelona: El Viejo Topo.

5. Luxemburgo, Rosa. (1969). Problemas de organización de la socialdemocracia rusa. En: Teoría marxista del partido político (pp. 63-95). Córdoba: Cuadernos de Pasado y Presente.

6. Machado, Decio y Zibechi, Raúl. (2016). Cambiar el mundo desde arriba. Los límites del progresismo. Bogotá, D. C.: Desde Abajo.

7. March, James. y Olsen, Johan. (1997). El redescubrimiento de las instituciones. México, D. F.: FCE.

8. Marx, Karl. (1985). El dieciocho brumario de Luis Bonaparte. En: Trabajo asalariado y capital (pp. 135-239). Bogotá, D. C.: Planeta.

9. Marzano, Michela. (2011). Preparados para triunfar. Barcelona: Tusquets.

10. McAdam, Doug; McCarthy, John y Zald, Mayer. (1999). Movimientos sociales, perspectivas comparadas. Madrid: Itsmo.

11. McAdam, Doug; Tarrow, Sidney y Tilly, Cherles. (2005). Dinámica de la contienda política. Barcelona: Hacer.

12. McCarthy, John. (1999). «Adoptar, adaptar e inventar límites y oportunidades». En: McAdam, Doug; McCarthy, John y Zald, Mayer (eds.). Movimientos sociales: perspectivas comparadas (pp. 205-220). Madrid: Itsmo.

13. Melucci, Alberto. (1999). Acción colectiva, vida cotidiana y democracia. México: El Colegio de México. 
14. Múnera, Leopoldo. (1998). Rupturas y continuidades. Poder y movimiento popular en Colombia 1968-1988. Bogotá, D. C.: Universidad Nacional de Colombia, Cerec.

15. Negri, Antonio y Hardt, Michael. (2001). Imperio. Bogotá: Desde Abajo.

16. Negri, Antonio y Hardt, Michael. (2004). Multitud. Barcelona: Debate.

17. Olson, Mancur. (1992). "La lógica de la acción colectiva». En Battle Albert (ed.). Diez textos básicos de ciencia política, (pp. 203-220). Barcelona: Ariel.

18. Rifkin, Jeremy. (2014). La era del acceso. Buenos Aires: Paidós.

19. Smelser, Neil. (1995). Teoría del comportamiento colectivo. México: FCE.

20. Tarrow, Sidney. (1997). El poder en movimiento. Madrid: Alianza.

21. Tilly, Charles y Wood, Lesley. (2010). Los movimientos sociales, 1768-2008. Barcelona: Crítica.

22. Touraine, Alain. (1987). El Regreso del actor. Buenos Aires: Eudeba.

23. Zibechi, Raúl. (2003). Genealogía de la revuelta. Buenos Aires: NordanComunidad, Letra Libre.

24. Zibechi, Raúl. (2006). Dispersar el poder. Buenos Aires: Tinta Limón.

25. Zibechi, Raúl. (2008). América Latina: periferias urbanas, territorios en resistencia. Bogotá: Desde Abajo.

26. Zibechi, Raúl. (2010). América Latina: contrainsurgencia y pobreza. Bogotá: Desde Abajo.

27. Zibechi, Raúl. (2015). Descolonizar el pensamiento crítico y las prácticas emancipatorias. Bogotá: Desde Abajo.

28. Zibechi, Raúl. (2017). Movimientos sociales en América Latina. El «otro mundo» en movimiento. Bogotá: Desde Abajo. 